\title{
ARTICLE
}

Received 29 Jan 2014 | Accepted 19 Aug 2014 | Published 25 Sep $2014 \quad$ DOI: 10.1038/ncomms6030

\section{Unexpected regioselective carbon-hydrogen bond activation/cyclization of indolyl aldehydes or ketones with alkynes to benzo-fused oxindoles}

\author{
Xingyan Liu', Gaocan Li ${ }^{1}$, Feijie Song ${ }^{1} \&$ Jingsong You ${ }^{1}$
}

Rhodium-catalyzed carbon-hydrogen bond activation has attracted great interest in the construction of carbon-carbon and carbon-heteroatom bonds. In recent years, transition metal-mediated oxygen transposition through a 'dehydration-rehydration' process has been considered as a promising strategy towards oxygen-functionalized compounds. Here we describe an unexpected rhodium-catalyzed regioselective carbon-hydrogen bond activation/ cyclization of easily available indolyl aldehydes or ketones with alkynes to afford benzo-fused oxindoles, involving the sequential carbonyl-assisted carbon-hydrogen activation of the indole ring at the 4-position, [4+2] cyclization, aromatization via dehydration, nucleophilic addition of water to iminium and oxidation. Isotopic labelling experiments disclose the occurrence of apparent oxygen transposition via dehydration-rehydration from the indolyl-3carbonyl group to the 2-position of pyrrole to forge a new carbonyl bond. The tandem reaction has been used as the key step for the concise synthesis of priolines, a type of alkaloid isolated from the roots of Salvia prionitis.

\footnotetext{
${ }^{1}$ Key Laboratory of Green Chemistry and Technology of Ministry of Education, College of Chemistry, and State Key Laboratory of Biotherapy, West China Hospital, West China Medical School, Sichuan University, 29 Wangjiang Road, Chengdu 610064, China. Correspondence and requests for materials should be addressed to J.Y. (email: jsyou@scu.edu.cn).
} 
$\mathrm{R}$ hodium-catalyzed $\mathrm{C}-\mathrm{H}$ bond activation has attracted great interest in the construction of carbon-carbon and carbon-heteroatom bonds ${ }^{1-5}$. In particular, the rhodium-catalyzed coupling reactions of (hetero)aromatic substrates with alkynes have offered a unique platform for atom-economical and straightforward annulation ${ }^{6-14}$. Recently, the research groups of Cheng and co-workers ${ }^{8}$, Glorius and co-workers ${ }^{9}$ and Jeganmohan and co-workers ${ }^{10}$ have disclosed the synthesis of indenols through the rhodium- or rutheniumcatalyzed carbonyl-assisted aromatic $\mathrm{C}-\mathrm{H}$ activation/cyclization of aryl ketones with internal alkynes via a proposed fivemembered metallocyclic intermediate (Fig. 1a). Shi and coworkers ${ }^{11}$ have developed the synthesis of indenone by rhodiumcatalyzed carbonyl-directed annulation of benzimides with internal alkynes (Fig. 1b). Aldehydes often exhibit a poor directing effect and thus examples are still significantly underrepresented ${ }^{15-17}$. Usually, (in situ) conversion to imines can solve this problem ${ }^{18-20}$. In almost all the previously reported cases, only olefination reactions were studied.

(Benzo-fused) oxindoles (indolin-2-ones) are important structural motifs frequently found in pharmaceuticals, natural products and biologically active molecules (for example, antitumor, antibacterial, insecticidal and anthelmintic properties), and are also versatile building blocks for the preparation of structurally complex compounds ${ }^{21-25}$. Therefore, the development of new strategies for the facile synthesis of the indolin-2-one scaffolds from easily available starting materials has been an active research area ${ }^{26-29}$. In an effort to explore the rhodium-catalyzed annulation of indolyl-3-aldehydes with internal alkynes to construct cyclopenta[b]indol-1-one or cyclopenta[b]indol-1-ol derivatives through the more reactive $\mathrm{C} 2-\mathrm{H}$ cleavage of indole, the benzo-fused oxindoles were obtained unexpectedly through the $\mathrm{C} 4-\mathrm{H}$ activation of indole (Fig. 1c) ${ }^{17,30,31}$, which were confirmed by single crystal X-ray diffraction analysis (Supplementary Figs 42 and 43). This tandem reaction was disclosed to involve an apparent oxygen transposition via dehydration-rehydration from the indolyl-3-carbonyl group to the pyrrole C2-position to forge a new carbonyl bond ${ }^{32-34}$. Based on mechanism investigation, the reactivity and the scope of reaction were further improved. In this work, we would also like to demonstrate the usefulness for the synthesis of natural products.

\section{Results}

Optimization of the reaction conditions for 3a. After we surprisingly observed that the reaction of $\mathrm{N}$-methyl-indolyl-3carbaldehyde 1a with diphenylacetylene $\mathbf{2 a}$ gave benzo-fused oxindole $3 \mathbf{a}$ in $39 \%$ yield in the presence of $2.5 \mathrm{~mol} \%$ of $\left[\mathrm{RhCp}^{\star} \mathrm{Cl}_{2}\right]_{2}, 10 \mathrm{~mol} \%$ of $\mathrm{AgSbF}_{6}$ and 2.0 equiv. of $\mathrm{Ag}_{2} \mathrm{CO}_{3}$ in dioxane at $120^{\circ} \mathrm{C}$ for $24 \mathrm{~h}$ (Fig. 2; Supplementary Table 1, entry 1 ), we started to optimize the reaction system. After screening the different $\mathrm{N}$-substituted indolyl-3-carbaldehydes, $\mathrm{N}$-phenylindolyl-3-carbaldehyde $\mathbf{1 b}$ afforded $\mathbf{3 b}$ in the highest yield of $57 \%$ yield (Supplementary Table 1, entries 1, 4 and 5). The choice of additive was very crucial for the present catalytic reaction. In the absence of $\mathrm{AgSbF}_{6}$, only a trace amount of $\mathbf{3} \mathbf{a}$ was obtained (Supplementary Table 1, entry 2). Both acids such as PivOH and bases such as CsOPiv could shut down the reactivity (Supplementary Table 1, entries 16-17). Other oxidants gave rise to $\mathbf{3 b}$ in significantly low yields and even could not deliver the desired product (for example, $\mathrm{Cu}(\mathrm{OAc})_{2}, \mathrm{PhI}(\mathrm{OAc})_{2}$ and $\mathrm{O}_{2}$ ) (Supplementary Table 1, entries 12-14). In the absence of $\mathrm{Ag}_{2} \mathrm{CO}_{3}$, the reaction did not occur (Supplementary Table 1, entry 15). Tetrahydrofuran (THF) proved to be the best among the solvents investigated (Supplementary Table 1, entries 5, 8-11). Increasing loading of $\left[\mathrm{Cp}^{*} \mathrm{RhCl}_{2}\right]_{2}$ to $3.5 \mathrm{~mol} \%$ resulted in a slightly improved yield of $67 \%$ (Supplementary Table 1, entry 21).

Substrate scope. With the optimized reaction conditions, the range of indolyl-3-aldehydes was evaluated as illustrated in Table 1 . We were pleased to find that a relatively broad scope of $N$-substituted indolyl aldehydes could efficiently couple with diphenylacetylene $\mathbf{2 a}$ to afford the benzo-fused oxindole a<smiles>[H][R]1c2ccccc2C([2H])(O)c2ccccc21</smiles>

b

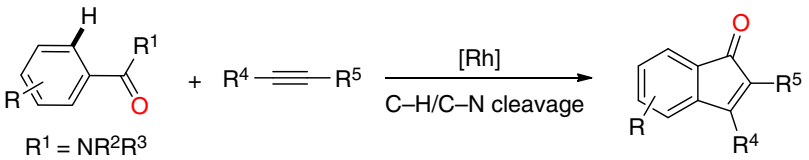

c<smiles>[R]c1ccccc1</smiles>

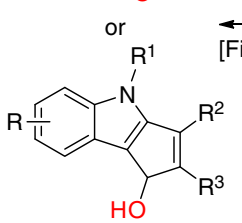

[Rh] $\underset{\text { [Five-membered rhodacycle] }}{\stackrel{x}{*}}$

$\mathrm{R}^{4}=\mathrm{H}$<smiles></smiles>
[Six-membered rhodacycle]<smiles></smiles>

\section{Cascade:}

- Regioselective $\mathrm{C}-\mathrm{H}$ activation

- Cyclization

- Oxygen transposition

Figure 1 | Rhodium- or ruthenium-catalyzed carbonyl-assisted (hetero)aromatic C-H activation/cyclization with internal alkynes. (a) In previous work, the preparation of indenols. (b) In previous work, the preparation of indenones. (c) In this report, regioselective carbon-hydrogen bond activation/ cyclization to benzo-fused oxindoles. 
derivatives 3 in synthetically useful yields. Both the $N$-alkyl and $N$-aryl substituents of indolyl-3-carbaldehydes had little effect on the yields except the $N$-methyl group (Table 1, 3a-3g). However, the $N$-acyl substituted indolyl-3-carbaldehydes could not deliver the desirable product. It is important to stress that the $N$-benzyl<smiles>O=Cc1cn([TlH])c2ccccc12</smiles><smiles>O=C1Nc2cccc3c(-c4ccccc4)c(-c4ccccc4)cc1c23</smiles>
1a, $R^{1}=\mathrm{Me}$
$1 \mathrm{~b}, \mathrm{R}^{1}=\mathrm{Ph}$
1c, $\mathrm{R}^{1}=\mathrm{Bn}$

Figure 2 | Optimization of the Rh-catalyzed tandem reaction of indolyl aldehydes with diphenyl acetylene. See the Supplementary Table 1 for details. substituted indolyl-3-aldehyde $1 \mathrm{c}$ gave rise to $3 \mathrm{c}$ in $63 \%$ yield, which may further be transformed to the free (NH)-product by removal of the benzyl group. The current catalytic system was tolerant to a variety of synthetically valuable functional groups such as ester, halide and alkyloxyl groups on both the pyrrole ring and the aromatic moiety, which would offer an opportunity for further synthetic transformations. To further expand the scope of the current rhodium catalytic protocol, indolyl-3-ketone was examined as a substrate. However, indolyl-3-ketone exhibited a much lower reactivity than indolyl-3-aldehyde. The coupling reaction of 1-(1-phenyl- $1 \mathrm{H}$-indol-3-yl)propan-1-one $\mathbf{1 n}$ with $\mathbf{2 a}$ gave $3 \mathbf{n}$ in only $30 \%$ yield.

To test the generality of this protocol, we next examined the scope of internal alkynes. As shown in Table 2, symmetrical diaryl alkynes, unsymmetrical aryl alkyl alkynes and dialkyl alkynes all could smoothly react with $\mathrm{N}$-phenyl-indole-3-carbaldehydes 1 to afford a variety of benzo-fused oxindoles. Symmetrical diaryl alkynes with both the electron-donating and electron-withdrawing groups could furnish the desired products (Table 2, 4a-4f). This method was compatible with some important

Table 1 | The scope of indolyl-3-aldehydes or ketones.
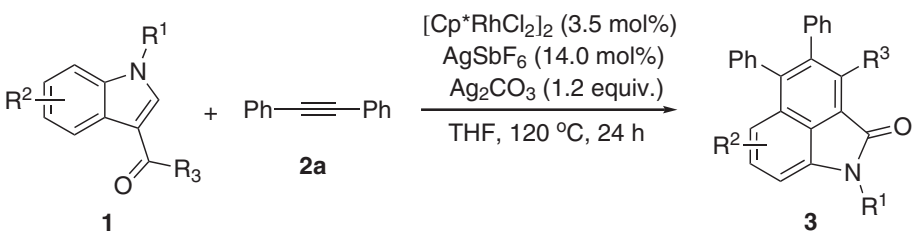<smiles>CN1C(=O)c2cc(-c3ccccc3)c(-c3ccccc3)c3cccc1c23</smiles>

3a, $46 \%{ }^{*}$

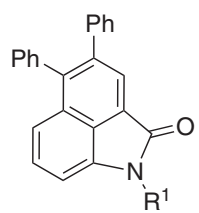

$\mathrm{R}^{1}=1$-Naphthyl

3 e, $55 \%$<smiles>COc1ccc2c3c(cc(-c4ccccc4)c(-c4ccccc4)c13)C(=O)N2c1ccccc1</smiles>

$3 \mathbf{i}, 76 \%$<smiles>CC(=O)c1cc2c3c(cc(-c4ccccc4)c(-c4ccccc4)c3c1)C(=O)N2c1ccccc1</smiles>

$3 m, 57 \%$<smiles>O=C1c2cc(-c3ccccc3)c(-c3ccccc3)c3cccc(c23)N1c1ccccc1</smiles>

3b, $67 \%$<smiles>O=C1Nc2cccc3c(-c4ccccc4)c(-c4ccccc4)cc1c23</smiles>

$\mathrm{R}^{1}=4-\mathrm{ClC}_{6} \mathrm{H}_{4}$

3f, $74 \%$<smiles>O=C1c2cc(-c3ccccc3)c(-c3ccccc3)c3c(OCc4ccccc4)ccc(c23)N1c1ccccc1</smiles>

$3 \mathbf{j}, 70 \%$<smiles>CCc1c(-c2ccccc2)c(-c2ccccc2)c2cccc3c2c1C(=O)N3c1ccccc1</smiles><smiles>O=C1c2cc(-c3ccccc3)c(-c3ccccc3)c3cccc(c23)N1Cc1ccccc1</smiles>

$3 c, 63 \%$<smiles>CCCN1C(=O)c2cc(-c3ccccc3)c(-c3ccccc3)c3cccc1c23</smiles>

$\mathrm{R}^{1}=4-\mathrm{MeOC}_{6} \mathrm{H}_{4}$

$3 g, 64 \%$<smiles>O=C1c2cc(-c3ccccc3)c(-c3ccccc3)c3c(Cl)ccc(c23)N1c1ccccc1</smiles>

$3 k, 58 \%$<smiles>CC(C)N1C(=O)c2cc(-c3ccccc3)c(-c3ccccc3)c3cccc1c23</smiles>

3d, $61 \%$<smiles>Cc1ccc2c(-c3ccccc3)c(-c3ccccc3)cc3c2c1C(=O)N3c1ccccc1</smiles>

$3 \mathrm{~h}, 68 \%$<smiles>O=C1c2cc(-c3ccccc3)c(-c3ccccc3)c3cc(Cl)cc(c23)N1c1ccccc1</smiles>

3I, $67 \%$

Reaction conditions: $\mathbf{2 a}(0.25 \mathrm{mmol}), \mathbf{1}$ (2.0 equiv.), $\left[\mathrm{Cp}^{\star} \mathrm{RhCl}_{2}\right]_{2}(3.5 \mathrm{~mol} \%), \mathrm{AgSbF}_{6}(14.0 \mathrm{~mol} \%), \mathrm{Ag}_{2} \mathrm{CO}_{3}(1.2$ equiv. $)$ and $\mathrm{THF}(3.0 \mathrm{ml})$ under $\mathrm{N}_{2}$ at $120{ }^{\circ} \mathrm{C}$ for $24 \mathrm{~h}$ ${ }^{*}\left[\mathrm{Cp}^{\star} \mathrm{RhCl}_{2}\right]_{2}(5.0 \mathrm{~mol} \%), \mathrm{AgSbF}_{6}(20 \mathrm{~mol} \%), \mathrm{Ag}_{2} \mathrm{CO}_{3}$ (2.0 equiv.) and $\mathrm{THF}(2.0 \mathrm{ml}$ ). 
Table 2 | The scope of alkynes.

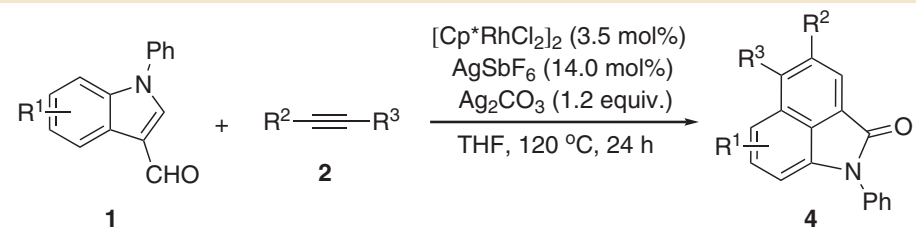<smiles>Cc1ccc(-c2cc3c4c(cccc4c2-c2ccc(C)cc2)N(c2ccccc2)C3=O)cc1</smiles>

$4 a, 60 \%$<smiles>O=C1c2cc(-c3ccc(Cl)cc3)c(-c3ccc(Cl)cc3)c3cccc(c23)N1c1ccccc1</smiles>

$4 e, 64 \%$<smiles></smiles>

$4 i, 55 \% *$<smiles></smiles>

4b, $71 \%$<smiles>O=C1c2cc(-c3ccc(Br)cc3)c(-c3ccc(Br)cc3)c3cccc(c23)N1c1ccccc1</smiles>

4f, $57 \%$<smiles></smiles>

4j, 55\%*<smiles>COc1ccc(-c2cc3c4c(cccc4c2-c2ccc(OC)cc2)N(c2ccccc2)C3=O)cc1</smiles>

4c, $53 \%{ }^{*}$<smiles>CCc1c(-c2ccccc2)cc2c3c(cccc13)N(c1ccccc1)C2=O</smiles>

4g, $57 \%$ *<smiles>O=C1c2cc(-c3ccc(F)cc3)c(-c3ccc(F)cc3)c3cccc(c23)N1c1ccccc1</smiles>

4d, $73 \%$<smiles>CCc1c(-c2ccccc2)cc2c3c(ccc(OC)c13)N(c1ccccc1)C2=O</smiles>

4h, $67 \%$ *

Reaction conditions: 2 ( $0.25 \mathrm{mmol}), 1$ (2.0 equiv.), $\left[\mathrm{Cp}^{\star} \mathrm{RhCl}_{2}\right]_{2}$ (3.5 mol\%), $\mathrm{AgSbF}_{6}(14.0 \mathrm{~mol} \%), \mathrm{Ag}_{2} \mathrm{CO}_{3}\left(1.2\right.$ equiv.) and $\mathrm{THF}(3.0 \mathrm{ml})$ under $\mathrm{N}_{2}$ at $120^{\circ} \mathrm{C}$ for $24 \mathrm{~h}$.

${ }^{\star}\left[\mathrm{Cp}^{\star} \mathrm{RhCl}_{2}\right]_{2}(5.0 \mathrm{~mol} \%), \mathrm{AgSbF}_{6}(20 \mathrm{~mol} \%), \mathrm{Ag}_{2} \mathrm{CO}_{3}(2.0$ equiv. $)$ and $\mathrm{THF}(2.0 \mathrm{ml})$.

functional groups such as methoxy, fluoro, chloro and bromo groups on the aromatic ring of alkynes. Unsymmetrical aryl alkyl alkynes gave the exclusively regioselective annulation, and the aryl group was installed at the 4-position of benzo-fused oxindole (Table 2, 4g-4i). Dialkyl alkynes exhibited slightly lower reactivity than diaryl alkynes (Table $2,4 \mathbf{j}$ ).

Mechanism investigation. To probe the plausible mechanism of the cascade reaction, a series of labelling experiments involving ${ }^{18} \mathrm{O}$ were carried out (Fig. 3; Supplementary Figs 44-48). The annulation of ${ }^{18} \mathrm{O}$-labelled 1 -(1-phenyl- $1 H$-indol-3-yl)propan-1one $\left({ }^{18} \mathrm{O}-1 \mathbf{n}\right)$ with diphenylacetylene 2 a could afford ${ }^{18} \mathrm{O}$-labelled benzo-fused oxindole $\left({ }^{18} \mathrm{O}-3 \mathrm{n}\right)$, which showed that the oxygen of the carbonyl group in the product originated from the initial

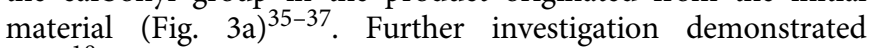
that ${ }^{18} \mathrm{O}$ could also be incorporated into benzo-fused oxindole 3n when extra ${ }^{18} \mathrm{O}$-labelled water was added into the reaction system, which suggested that water might be produced and then participate in an apparent oxygen transposition in the cascade reaction (Fig. 3b) 38,39 .
On the basis of these above observations, a tentative mechanism of this transformation was proposed to involve the aromatic C4-H activation/cyclization/aromatization via dehydration/nucleophilic addition/oxidation cascade pathway (Fig. 4). We hypothesized that the first step of the catalytic cycle was the formation of the highly electrophilic [ $\mathrm{Rh}(\mathrm{III}) \mathrm{Cp}^{*}$ ] species $\mathbf{A}$ in situ generated from the reaction of $\left[\mathrm{RhCp}^{*} \mathrm{Cl}_{2}\right]_{2}$ with $\mathrm{AgSbF}_{6}$. Subsequently, the $\mathrm{Rh}$-catalyzed carbonyl-directed regioselective aromatic $\mathrm{C} 4-\mathrm{H}$ activation produced the six-membered rhodacycle $\mathbf{B}$ rather than the five-membered rhodium intermediate via the pyrrole $\mathrm{C} 2-\mathrm{H}$ bond activation. An internal alkyne then regioselectively inserted into the rhodium-carbon bond to give an eight-membered rhodacycle $\mathbf{C}$, followed by an intramolecular insertion of the carbonyl group into the rhodium-alkenyl bond to generate the rhodium alkoxide intermediate D (refs 40-43). Subsequent protonation of $\mathbf{D}$ provided the possible alcohol intermediate $\mathbf{E}$ (refs 8-10) and regenerated the active $\mathrm{Rh}$ (III) species. The intermediate $\mathbf{E}$ underwent aromatization via dehydration to yield the iminium intermediate F (refs 44-47), followed by nucleophilic attack of water. The resulting intermediate $\mathbf{G}$ was reoxidized by $\mathrm{Ag}(\mathrm{I})$ to furnish the final 
a

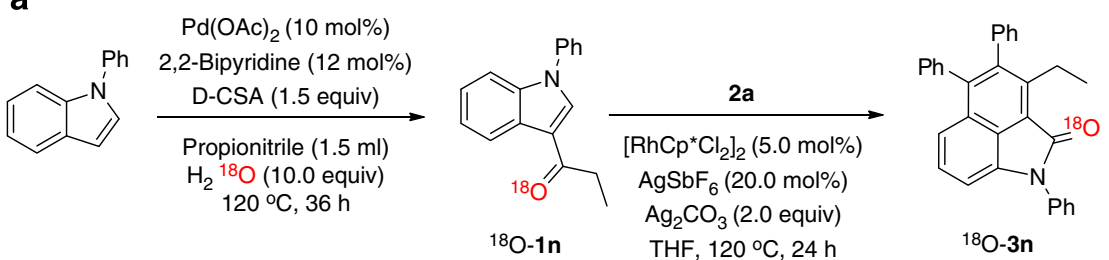

b

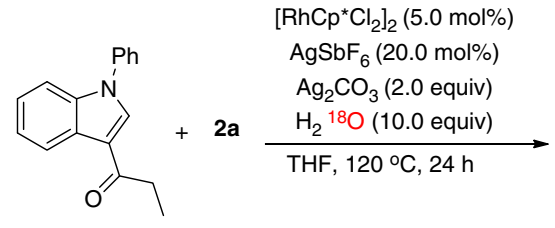

1n<smiles>CCc1c2c3c(c(-c4ccccc4)c1-c1ccccc1)C=CC=C2N(c1ccccc1)C3=O</smiles>

${ }^{180} \mathrm{O}-3 \mathrm{n}$

Figure 3 | Labelling experiments involving ${ }^{18} \mathbf{O}$. (a) The annulation of ${ }^{18} \mathrm{O}$-labelled 1-(1-phenyl-1H-indol-3-yl)propan-1-one $\left({ }^{18} \mathrm{O}-\mathbf{1 n}\right)$ with diphenylacetylene $\mathbf{2 a}$. For high-resolution mass spectrometry (HRMS) spectrum of ${ }^{18} \mathrm{O}-\mathbf{1 n}$, see Supplementary Fig. 44 . For HRMS spectrum of ${ }^{18} \mathrm{O}-\mathbf{3 n}$ obtained from ${ }^{18} \mathrm{O}-\mathbf{1 n}$, see Supplementary Fig. 45. (b) The annulation of 1-(1-phenyl-1H-indol-3-yl)propan-1-one (1n) with diphenylacetylene $\mathbf{2 a}$ in the presence of extra ${ }^{18} \mathrm{O}$-labelled $\mathrm{H}_{2} \mathrm{O}$. For HRMS spectrum of ${ }^{18} \mathrm{O}-\mathbf{3 n}$, see Supplementary Fig. 46. D-CSA, D- $(+)$-camphorsulfonic acid.

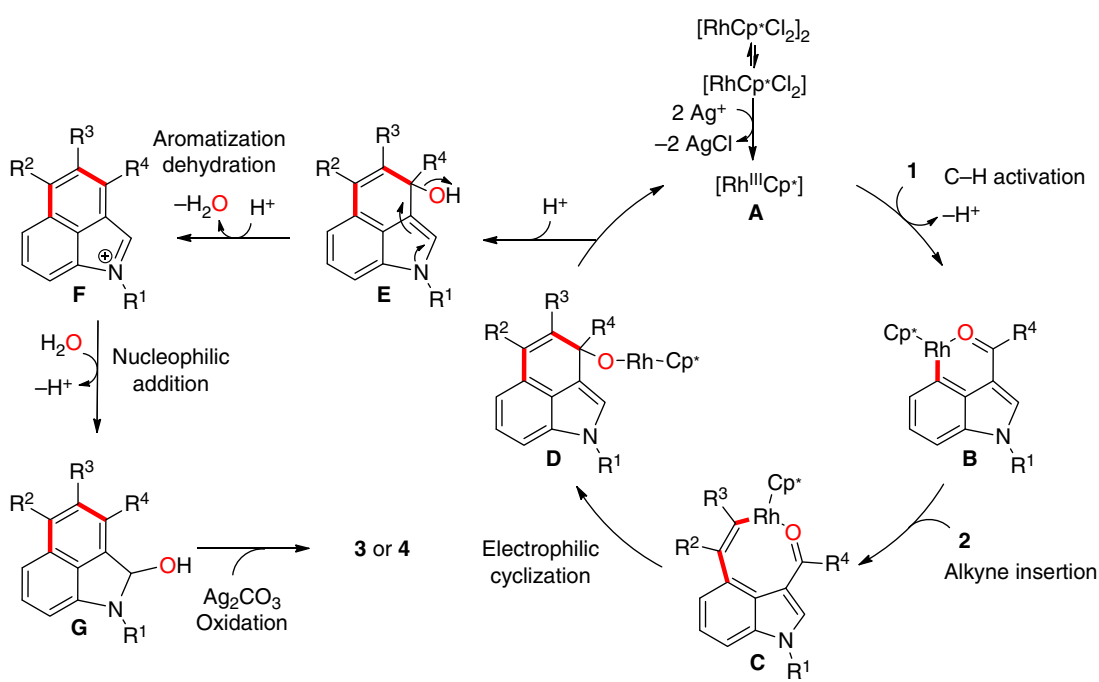

Figure 4 | Plausible catalytic cycle. The possible mechanism involves the sequential Rh-catalyzed carbonyl-assisted regioselective aromatic $\mathrm{C} 4-\mathrm{H}$ activation/[4+2] cyclization/aromatization via dehydration/nucleophilic addition of water/oxidation.

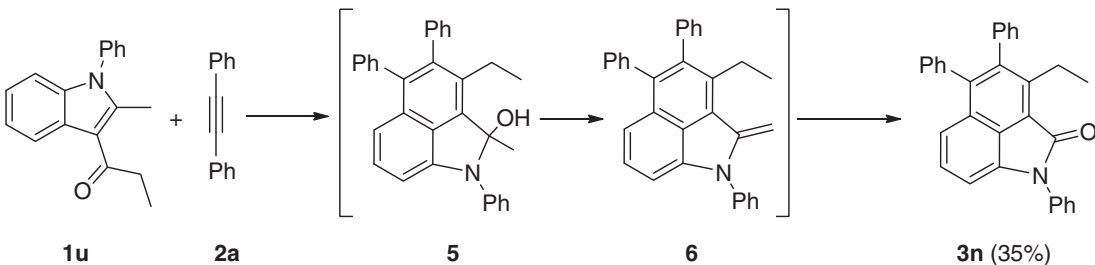

Figure 5 | The coupling of 1-(2-methyl-1-phenyl-1H-indol-3-yl)propan-1-one 1u with diphenyl acetylene 2a. Reaction conditions: $\mathbf{2 a}(0.25 \mathrm{mmol})$, 1u (2.0 equiv.), $\left[\mathrm{Cp}^{\star} \mathrm{RhCl}_{2}\right]_{2}$ (5.0 mol\%), $\mathrm{AgSbF}_{6}(20.0 \mathrm{~mol} \%), \mathrm{Ag}_{2} \mathrm{CO}_{3}$ (2.0 equiv.), $\mathrm{H}_{2} \mathrm{O}\left(2.5 \mathrm{mmol}\right.$ ) and THF (2.0 ml) under $\mathrm{N}_{2}$ at $120{ }^{\circ} \mathrm{C}$ for $24 \mathrm{~h}$.

product, which fulfilled an apparent oxygen transposition via dehydration-rehydration to forge a new carbonyl bond.

To further clarify the proposed mechanism, the electrospray ionization-high-resolution mass spectrometry analysis of the reaction between $\mathrm{N}$-phenyl-indolyl-3-carbaldehyde $\mathbf{1 b}$ and diphenylacetylene 2a was performed to capture the possible alcohol intermediate. Fortunately, a peak at m/z 400.1707 appeared, which was in accordance with the intermediate $\mathbf{E}\left(\mathrm{R}^{1}, \mathrm{R}^{2}\right.$, $\mathrm{R}^{3}=$ Phenyl; $\left.\mathrm{R}^{4}=\mathrm{H}\right)\left([\mathrm{M}+\mathrm{H}]^{+}\right.$, MW 400.1701) illustrated in
Fig. 4 (Supplementary Fig. 49 and Supplementary Methods). However, attempts to separate the intermediate $\mathbf{E}$ from the reaction system failed probably due to the rapid dehydration of $\mathbf{E}$.

Subsequently, we tried to use 1-(2-methyl-1-phenyl- $1 H$-indol3-yl)propan-1-one $\mathbf{1 u}$ with a methyl substituent at the indole C2position as a reaction substrate to isolate the 3-ethyl-2-methyl1,4,5-triphenyl-1,2-dihydrobenzo $[c d]$ indol-2-ol intermediate $\mathbf{5}$ (Fig. 5). To our surprise, $\mathbf{1 u}$ did give rise to the same benzo-fused oxindole product $\mathbf{3 n}$ as that of the 2 -unsubstituted 
Table 3 | The reaction of indolyl ketones with alkynes.
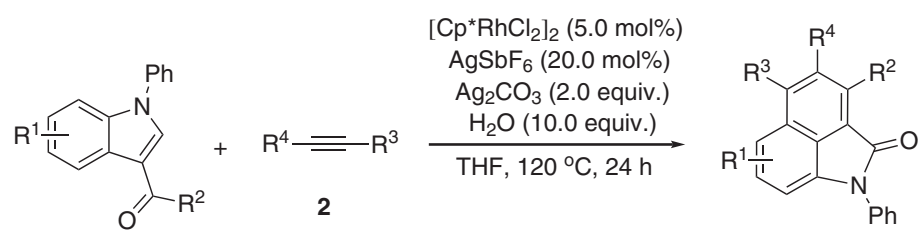

1

3<smiles>CCc1c(-c2ccccc2)c(-c2ccccc2)c2cccc3c2c1C(=O)N3c1ccccc1</smiles>

$3 n, 61 \%$<smiles>Cc1c(-c2ccccc2)c(-c2ccccc2)c2cccc3c2c1C(=O)N3c1ccccc1</smiles>

$30,62 \%$<smiles>O=C1c2c(Br)c(-c3ccccc3)c(-c3ccccc3)c3cccc(c23)N1c1ccccc1</smiles>

$3 p, 71 \%$<smiles>O=C1c2c(-c3ccccc3)c(-c3ccccc3)c(-c3ccccc3)c3cc(Cl)cc(c23)N1c1ccccc1</smiles>

$3 q, 61 \%$<smiles>COc1ccc(-c2c(C)c(-c3ccc(OC)cc3)c3cccc4c3c2C(=O)N4c2ccccc2)cc1</smiles>

$3 r, 57 \%$<smiles>Cc1ccc(-c2c(-c3ccc(C)cc3)c3c4c(cccc4c2Cc2ccccc2)N(c2ccccc2)C3=O)cc1</smiles>

3s, $60 \%$<smiles>CCc1c(-c2ccccc2)c(Cc2ccccc2)c2c3c(ccc(OC)c13)N(c1ccccc1)C2=O</smiles>

$3 \mathbf{t}, 53 \%$

Reaction conditions: $2(0.25 \mathrm{mmol}), \mathbf{1}$ (2.0 equiv.), $\left[\mathrm{Cp}^{\star} \mathrm{RhCl}_{2}\right]_{2}\left(5.0 \mathrm{~mol}^{2}\right), \mathrm{AgSbF}_{6}(20.0 \mathrm{~mol} \%), \mathrm{Ag}_{2} \mathrm{CO}_{3}\left(2.0\right.$ equiv.), $\mathrm{H}_{2} \mathrm{O}\left(10.0\right.$ equiv.) and THF (2.0 ml) under $\mathrm{N}_{2}$ at $120{ }^{\circ} \mathrm{C}$ for $24 \mathrm{~h}$.

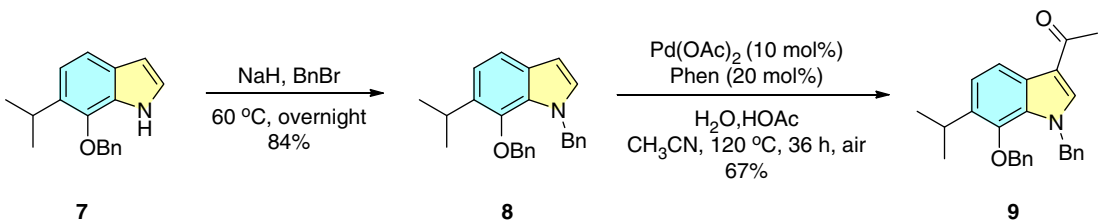

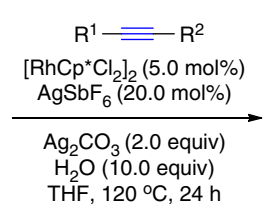

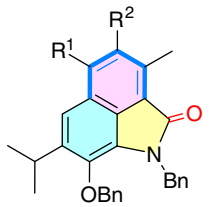

$10 a, R^{1}=P h, R^{2}=P h, 53 \%$

10b, $R^{1}=E t, R^{2}=P h, 40 \%$

10c, $\mathrm{R}^{1}=n-\operatorname{Pr}, \mathrm{R}^{2}=n-\operatorname{Pr}, 24 \%$

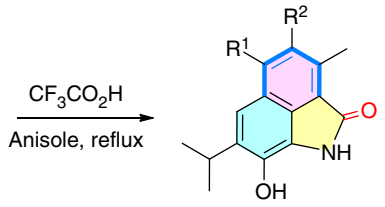

11a, $\mathrm{R}^{1}=\mathrm{Ph}, \mathrm{R}^{2}=\mathrm{Ph}, 72 \%$ 11b, $R^{1}=E t, R^{2}=P h, 68 \%$ 11c, $\mathrm{R}^{1}=n-\operatorname{Pr}, \mathrm{R}^{2}=n-\operatorname{Pr}, 56 \%$

Figure 6 | Synthesis of priolines 11a-11c. The current tandem reaction was used to construct the key benzo-fused oxindole scaffolds 10a-10c in the synthesis of a type of alkaloid isolated from the roots of Salvia prionitis. Phen, 1,10-phenanthroline.

1-(1-phenyl-1H-indol-3-yl)propan-1-one 1n. We assumed that one of the hydrogen atoms of the methyl group at the C2-position might undergo intramolecular dehydration to form the intermediate 6 (refs 9,10), followed by the oxidation of the terminal alkenyl group to furnish the benzo-fused oxindole $\mathbf{3 n}$ in the presence of an excess amount of silver salt ${ }^{48}$. These unexpected observations also well-demonstrated the proposed mechanistic pathway involving the formation of the alcohol intermediate $\mathbf{G}$ illustrated in Fig. 4.

Improvement of the reactivity and the scope of reaction. On the basis of the proposed mechanism, we re-examined the reactivity of indolyl ketones with alkynes by the addition of extra water into the reaction system. As expected, the yields of benzo-fused oxindoles were improved significantly. The yield of 1-(1-phenyl$1 \mathrm{H}$-indol-3-yl)propan-1-one $\mathbf{1 n}$ with diphenyl acetylene $\mathbf{2 a}$ was increased from 30 to $61 \%$ in the presence of 10.0 equiv. of $\mathrm{H}_{2} \mathrm{O}$ (Comparing $\mathbf{3 n}$ in Table 3 with $\mathbf{3 n}$ in Table 1 ). As shown in Table 3 , the cascade reaction also exhibited a relatively wide scope of substrates including both indolyl ketones and alkynes. It is worthy to note that unsymmetrical aryl alkyl alkyne could smoothly undergo the regioselective annulation to afford benzofused oxindole (Table 3, 3t). In addition, when indolyl aldehydes were used as the substrate, the yields of benzo-fused oxindoles could be increased by $\sim 5 \%$. 
Synthesis of priolines. Priolines, a type of alkaloid, are isolated from the roots of Salvia prionitis ${ }^{25}$. To further elucidate the usefulness of our methodology, the concise synthesis of priolines was performed in four steps starting from7-benzyloxy-6isopropylindole 7 (ref. 49) (For 11a, 21.5\% total yield; 11b, $15.3 \%$ total yield; 11c, $7.6 \%$ total yield; Fig. 6). First, compound 7 reacted with benzyl bromide furnished the $N$-benzyl indole $\mathbf{8}$ in $84 \%$ yield. Subsequently, the acylation at the indole C3-position afforded the crucial intermediate 3 -acylated indole 9 in $67 \%$ yield by taking advantage of our previously reported method ${ }^{50}$. Indolyl ketone 9 next underwent a regioselective carbon-hydrogen activation/cyclization to give the $\mathrm{N}$ - and $\mathrm{O}$-protected priolines 10. Finally, debenzylation of $\mathbf{1 0}$ with trifluoroacetic acid and anisole gave rise to the targeted compounds $\mathbf{1 1}$.

\section{Discussion}

An unprecedented rhodium-catalyzed regioselective carbonhydrogen activation/cyclization has been disclosed to synthesize benzo-fused oxindoles from easily available indolyl-3-aldehydes or ketones and alkynes, which involves the sequential $\mathrm{Rh}$ catalyzed carbonyl-assisted regioselective aromatic $\mathrm{C} 4-\mathrm{H}$ activation/[4+2] cyclization/aromatization via dehydration/ nucleophilic addition of water/oxidation. On the basis of a primary mechanistic investigation, it is found that the addition of extra water can significantly improve the reactivity of indolyl-3ketones. The catalytic reaction exhibits a high regioselectivity with unsymmetrical alkynes. In addition, the regioselective carbon-hydrogen activation/cyclization has been utilized as the key step for the concise synthesis of priolines. We anticipate that this rhodium-mediated apparent oxygen transposition via dehydration-rehydration would provide us an inspiration for the development of novel and innovative transformations involving a rhodium alkoxide intermediate. This unexpected finding would be useful in the synthesis of natural products and a detailed mechanistic investigation is ongoing in our group.

\section{Methods \\ General. For ${ }^{1} \mathrm{H}$ and ${ }^{13} \mathrm{C}$ NMR analysis of the compounds in this article, see Supplementary Figs 1-41.}

General procedure for the reaction of indolyl aldehydes. A flame-dried Schlenk tube with a magnetic stir bar was charged with $\left[\mathrm{Cp}^{*} \mathrm{RhCl}_{2}\right]_{2}(5.4 \mathrm{mg}, 8.75 \mu \mathrm{mol}$, $3.5 \mathrm{~mol} \%)$, alkyne $(0.25 \mathrm{mmol}, 1.0$ equiv.), indolyl aldehyde ( $0.5 \mathrm{mmol}, 2.0$ equiv.), $\mathrm{AgSbF}_{6}(12.0 \mathrm{mg}, 0.035 \mathrm{mmol}, 14 \mathrm{~mol} \%), \mathrm{Ag}_{2} \mathrm{CO}_{3}(82.7 \mathrm{mg}, 0.3 \mathrm{mmol}, 1.2$ equiv.) and THF ( $3.0 \mathrm{ml})$ under $\mathrm{N}_{2}$. The tube was sealed with a teflon-coated screw cap and the reaction solution was heated at $120^{\circ} \mathrm{C}$ for $24 \mathrm{~h}$. The mixture was then cooled to ambient temperature, diluted with $10 \mathrm{ml}$ of $\mathrm{CH}_{2} \mathrm{Cl}_{2}$, filtered through a celite pad and washed with $10-20 \mathrm{ml}$ of $\mathrm{CH}_{2} \mathrm{Cl}_{2}$. The combined organic phases were concentrated and the residue was purified by column chromatography on neutral alumina or silica gel to provide the desired product.

General procedure for the reaction of indolyl ketones. A flame-dried Schlenk tube with a magnetic stir bar was charged with $\left[\mathrm{Cp}^{*} \mathrm{RhCl}_{2}\right]_{2}(7.8 \mathrm{mg}, 12.5 \mu \mathrm{mol}$, $5.0 \mathrm{~mol} \%)$, alkyne ( $0.25 \mathrm{mmol}, 1.0$ equiv.), indolyl ketone $(0.5 \mathrm{mmol}, 2.0$ equiv.), $\mathrm{AgSbF}_{6}(17.2 \mathrm{mg}, 0.05 \mathrm{mmol}, 20 \mathrm{~mol} \%), \mathrm{Ag}_{2} \mathrm{CO}_{3}$ (137.9 mg, $0.5 \mathrm{mmol}, 2.0$ equiv.), $\mathrm{H}_{2} \mathrm{O}(45 \mu \mathrm{l}, 2.5 \mathrm{mmol}, 10.0$ equiv. $)$ and THF $(2.0 \mathrm{ml})$ under $\mathrm{N}_{2}$. The tube was sealed with a teflon-coated screw cap and the reaction solution was heated at $120^{\circ} \mathrm{C}$ for $24 \mathrm{~h}$. The mixture was then cooled to ambient temperature, diluted with $10 \mathrm{ml}$ of $\mathrm{CH}_{2} \mathrm{Cl}_{2}$, filtered through a celite pad and washed with $10-20 \mathrm{ml}$ of $\mathrm{CH}_{2} \mathrm{Cl}_{2}$. The combined organic phases were concentrated and the residue was purified by column chromatography on silica gel to provide the desired product.

\section{References}

1. Bouffard, J. \& Itami, K. Rhodium-catalyzed C-H bond arylation of arenes. Top. Curr. Chem. 292, 231-280 (2010).

2. Patureau, F. W., Wencel-Delord, J. \& Glorius, F. Cp*Rh-catalyzed C-H activations: versatile dehydrogenative cross-couplings of $\mathrm{C}_{\mathrm{sp} 2} \mathrm{C}-\mathrm{H}$ positions with olefins, alkynes, and arenes. Aldrichimica Acta 45, 31-41 (2012).
3. Lewis, J. C., Bergman, R. G. \& Ellman, J. A. Direct functionalization of nitrogen heterocycles via Rh-catalyzed C-H bond activation. Acc. Chem. Res. 41, 1013-1025 (2008).

4. Colby, D. A., Bergman, R. G. \& Ellman, J. A. Rhodium-catalyzed C-C bond formation via heteroatom-directed $\mathrm{C}-\mathrm{H}$ bond activation. Chem. Rev. 110, 624-655 (2010).

5. Colby, D. A., Tsai, A. S., Bergman, R. G. \& Ellman, J. A. Rhodium catalyzed chelation-assisted C-H bond functionalization reactions. Acc. Chem. Res. 45, 814-825 (2012).

6. Song, G., Wang, F. \& Li, X. C-C, C-O and C-N bond formation via rhodium(III)-catalyzed oxidative C-H activation. Chem. Soc. Rev. 41, 3651-3678 (2012).

7. Satoh, T. \& Miura, M. Oxidative coupling of aromatic substrates with alkynes and alkenes under rhodium catalysis. Chem. Eur. J. 16, 11212-11222 (2010).

8. Muralirajan, K., Parthasarathy, K. \& Cheng, C.-H. Regioselective synthesis of indenols by rhodium-catalyzed $\mathrm{C}-\mathrm{H}$ activation and carbocyclization of aryl ketones and alkynes. Angew. Chem. Int. Ed. 50, 4169-4172 (2011).

9. Patureau, F. W., Besset, T., Kuhl, N. \& Glorius, F. Diverse strategies toward indenol and fulvene derivatives: Rh-catalyzed $\mathrm{C}-\mathrm{H}$ activation of aryl ketones followed by coupling with internal alkynes. J. Am. Chem. Soc. 133, 2154-2156 (2011).

10. Chinnagolla, R. K. \& Jeganmohan, M. Ruthenium-catalyzed regioselective cyclization of aromatic ketones with alkynes: an efficient route to indenols and benzofulvenes. Eur. J. Org. Chem. 417-423 (2012).

11. Li, B.-J., Wang, H.-Y., Zhu, Q.-L. \& Shi, Z.-J. Rhodium/Copper-catalyzed annulation of benzimides with internal alkynes: indenone synthesis through sequential C-H and C-N cleavage. Angew. Chem. Int. Ed. 51, 3948-3952 (2012).

12. Stuart, D. R., Bertrand-Laperle, M., Burgess, K. M. N. \& Fagnou, K. Indole synthesis via rhodium catalyzed oxidative coupling of acetanilides and internal alkynes. J. Am. Chem. Soc. 130, 16474-16475 (2008).

13. Umeda, N., Tsurugi, H., Satoh, T. \& Miura, M. Fluorescent naphthyl- and anthrylazoles from the catalytic coupling of phenylazoles with internal alkynes through the cleavage of multiple $\mathrm{C}-\mathrm{H}$ bonds. Angew. Chem. Int. Ed. 47, 4019-4022 (2008).

14. Jayakumar, J., Parthasarathy, K. \& Cheng, C.-H. One-pot synthesis of isoquinolinium salts by rhodium-catalyzed $\mathrm{C}-\mathrm{H}$ bond activation: application to the total synthesis of oxychelerythrine. Angew. Chem. Int. Ed. 51, 197-200 (2012).

15. Park, S. H., Kim, J. Y. \& Chang, S. Rhodium-catalyzed selective olefination of arene esters via C-H bond activation. Org. Lett. 13, 2372-2375 (2011).

16. Padala, K. \& Jeganmohan, M. Highly regio- and stereoselective ruthenium(II)-catalyzed direct ortho-alkenylation of aromatic and heteroaromatic aldehydes with activated alkenes under open atmosphere. Org. Lett. 14, 1134-1137 (2012).

17. Lanke, V. \& Prabhu, K. R. Regioselective synthesis of 4-substituted indoles via $\mathrm{C}-\mathrm{H}$ activation: a ruthenium catalyzed novel directing group strategy. $\mathrm{Org}$. Lett. 15, 6262-6265 (2013).

18. Chen, S., Yu, J., Jiang, Y., Chen, F. \& Cheng, J. Rhodium-catalyzed direct annulation of aldehydes with alkynes leading to indenones: proceeding through in situ directing group formation and removal. Org. Lett. 15, 4754-4757 (2013).

19. Tan, P. W., Juwaini, N. A. B. \& Seayad, J. Rhodium(III)-amine dual catalysis for the oxidative coupling of aldehydes by directed $\mathrm{C}-\mathrm{H}$ activation: synthesis of phthalides. Org. Lett. 15, 5166-5169 (2013).

20. Zhang, T., Wu, L. \& Li, X. Rh(III)-catalyzed olefination of $N$-sulfonyl imines: synthesis of ortho-olefinated benzaldehydes. Org. Lett. 15, 6294-6297 (2013).

21. Galliford, C. V. \& Scheidt, K. A. Pyrrolidinyl-spirooxindole natural products as inspirations for the development of potential therapeutic agents. Angew. Chem. Int. Ed. 46, 8748-8758 (2007).

22. Lin, H. \& Danishefsky, S. J. Gelsemine: a thought-provoking target for total synthesis. Angew. Chem. Int. Ed. 42, 36-51 (2003).

23. Li, X. et al. Novel DNA intercalators without basic side chains as efficient antitumor agents: design, synthesis and evaluation of benzo- $[c, d]$-indolmalononitrile derivatives. Bioorg. Med. Chem. 18, 3279-3284 (2010).

24. Kumar, V., Poonam, Prasad, A. K. \& Parmar, V. S. Naturally occurring aristolactams, aristolochic acids and dioxoaporphines and their biological activities. Nat. Prod. Rep. 20, 565-583 (2003).

25. Li, M., Zhang, J.-S., Ye, Y.-M. \& Fang, J.-N. Constituents of the roots of salvia prionitis. J. Nat. Prod. 63, 139-141 (2000).

26. Li, J., Wang, N., Li, C. \& Jia, X. Construction of naphtho-fused oxindoles via the aryne diels-alder reaction with methyleneindolinones. Org. Lett. 14, 4994-4997 (2012).

27. Sheikh, M. C. et al. Studies on the lossen-type rearrangement of $\mathrm{N}$-(3-phenylpropionyloxy)phthalimide and $\mathrm{N}$-tosyloxy derivatives with several nucleophiles. Tetrahedron 66, 2132-2140 (2010).

28. Park, K.-Y., Kim, B. T. \& Heo, J.-N. Direct one-pot synthesis of naphthoxindoles from 4-bromooxindoles by suzuki-miyaura coupling and aldol condensation reactions. Eur. J. Org. Chem. 164-170 (2014). 
29. Nassar-Hardy, L., Deraedt, C., Fouquet, E. \& Felpin, F.-X. A fully palladiummediated construction of phenanthrenes and naphthoxindoles. Eur. J. Org. Chem. 4616-4622 (2011).

30. Liu, Q., Li, Q., Ma, Y. \& Jia, Y. Direct olefination at the C-4 position of tryptophan via $\mathrm{C}-\mathrm{H}$ activation: application to biomimetic synthesis of clavicipitic acid. Org. Lett. 15, 4528-4531 (2013).

31. Vadola, P. A. \& Sames, D. Catalytic coupling of arene C-H bonds and alkynes for the synthesis of coumarins: substrate scope and application to the development of neuroimaging agents. J. Org. Chem. 77, 7804-7814 (2012).

32. Trost, B. M., Maulide, N. \& Rudd, M. T. Ruthenium-catalyzed crosscoupling of tertiary propargyl alcohols with $\omega$-alkynenitriles: a regio- and stereoselective surrogate for an aldol condensation. J. Am. Chem. Soc. 131, 420-421 (2009).

33. Li, Z. et al. Scope and mechanistic analysis of the enantioselective synthesis of allenes by rhodium-catalyzed tandem ylide formation/[2,3]-sigmatropic rearrangement between donor/acceptor carbenoids and propargylic alcohols. J. Am. Chem. Soc. 134, 15497-15504 (2012).

34. Liu, J., Liu, Z., Wu, N., Liao, P. \& Bi, X. Silver-catalyzed cross-coupling of propargylic alcohols with isocyanides: an atom-economical synthesis of 2,3-allenamides. Chem. Eur. J. 20, 2154-2158 (2014).

35. Ding, S. \& Jiao, N. Direct transformation of $N, N$-dimethylformamide to $-\mathrm{CN}$ : Pd-catalyzed cyanation of heteroarenes via $\mathrm{C}-\mathrm{H}$ functionalization. J. Am. Chem. Soc. 133, 12374-12377 (2011).

36. Jiang, T.-S. \& Wang, G.-W. Synthesis of 3-acylindoles by palladiumcatalyzed acylation of free $(\mathrm{N}-\mathrm{H})$ indoles with nitriles. Org. Lett. 15, 788-791 (2013).

37. Dole, M. The chemistry of the isotopes of oxygen. Chem. Rev. 51, 263-300 (1952).

38. Shi, Z., Koester, D. C., Boultadakis-Arapinis, M. \& Glorius, F. Rh(III)-catalyzed synthesis of multisubstituted isoquinoline and pyridine $\mathrm{N}$-oxides from oximes and diazo compounds. J. Am. Chem. Soc. 135, 12204-12207 (2013).

39. Lian, Y., Bergman, R. G., Lavis, L. D. \& Ellman, J. A. Rhodium(III)-catalyzed indazole synthesis by $\mathrm{C}-\mathrm{H}$ bond functionalization and cyclative capture. J. Am. Chem. Soc. 135, 7122-7125 (2013).

40. Kuhl, N., Schröder, N. \& Glorius, F. Formal $\mathrm{S}_{\mathrm{N}}$-type reactions in rhodium (III)-catalyzed C-H bond activation. Adv. Synth. Catal. 356, 1443-1460 (2014).

41. Zhang, X.-S., Chen, K. \& Shi, Z.-J. Transition metal-catalyzed direct nucleophilic addition of $\mathrm{C}-\mathrm{H}$ bonds to carbon-heteroatom double bonds. Chem. Sci. 5, 2146-2159 (2014).

42. Wang, D., Wang, F., Song, G. \& Li, X. Diverse reactivity in a rhodium(III)catalyzed oxidative coupling of $\mathrm{N}$-allyl arenesulfonamides with alkynes. Angew. Chem. Int. Ed. 51, 12348-12352 (2012).

43. Tran, D. N. \& Cramer, N. Enantioselective rhodium(I)-catalyzed [3+2] annulations of aromatic ketimines induced by directed C-H activations. Angew. Chem. Int. Ed. 50, 11098-11102 (2011).

44. Li, C.-J. Cross-dehydrogenative coupling (CDC): exploring $\mathrm{C}-\mathrm{C}$ bond formations beyond functional group transformations. Acc. Chem. Res. 42, 335-344 (2009).
45. Zhang, C., Tang, C. \& Jiao, N. Recent advances in copper-catalyzed dehydrogenative functionalization via a single electron transfer (SET) process. Chem. Soc. Rev. 41, 3464-3484 (2012).

46. Guo, C., Song, J., Luo, S.-W. \& Gong, L.-Z. Enantioselective oxidative crosscoupling reaction of 3-indolylmethyl $\mathrm{C}-\mathrm{H}$ bonds with 1,3-dicarbonyls using a chiral lewis acid-bonded nucleophile to control stereochemistry. Angew. Chem. Int. Ed. 49, 5558-5562 (2010).

47. Flann, C. J. \& Overman, L. E. Enantioselective total synthesis of streptazolin. The tandem use of iminium ion-vinylsilane cyclizations and intramolecular acylations. J. Am. Chem. Soc. 109, 6115-6118 (1987).

48. Casades, I., Alvaro, M., García, H. \& Esplá, M. Evidence for an acid-catalysed reaction subordinated to the occurrence of a previous electron transfer in the incorporation of an electron-rich alkene within $\mathrm{NaY}$ zeolite. Chem. Commun. 982-983 (2001).

49. Garg, N. K., Sarpong, R. \& Stoltz, B. M. The first total synthesis of dragmacidin D. J. Am. Chem. Soc. 124, 13179-13184 (2002).

50. Ma, Y., You, J. \& Song, F. Facile access to 3-acylindoles through palladiumcatalyzed addition of indoles to nitriles: the one-pot synthesis of indenoindolones. Chem. Eur. J. 19, 1189-1193 (2013).

\section{Acknowledgements}

We acknowledge support for this work from the National Basic Research Programme of China (973 Programme, 2011CB808600) and the National NSF of China (21272160, 21432005, 21025205 and 21321061).

\section{Author contributions}

X.L. and G.L. performed the experiments and analyzed the data. F.S. and J.Y. designed and directed the project and wrote the manuscript. All authors contributed to the discussions.

\section{Additional information}

Accession codes: The X-ray crystallographic coordinates for structures reported in this article have been deposited at the Cambridge Crystallographic Data Centre (CCDC), under deposition number CCDC 979092 (3a) and CCDC 979091 (3n). These data can be obtained free of charge from The Cambridge Crystallographic Data Centre via www.ccdc.cam.ac.uk/data_request/cif.

Supplementary Information accompanies this paper at http://www.nature.com/ naturecommunications

Competing financial interests: The authors declare no competing financial interests.

Reprints and permission information is available online at http://npg.nature.com/ reprintsandpermissions/

How to cite this article: Liu, X. et al. Unexpected regioselective carbon-hydrogen bond activation/cyclization of indolyl aldehydes or ketones with alkynes to benzo-fused oxindoles. Nat. Commun. 5:5030 doi: 10.1038/ncomms6030 (2014). 